\title{
Improved Power Quality in an Innovative Bidirectional Inverter Topology
}

\author{
Sébastien Bissey ${ }^{1}$, Sébastien Jacques ${ }^{1}$, Jean-Charles Le Bunetel ${ }^{1}$, Sebastian Miranda ${ }^{1}$, \\ Yves Raingeaud $^{1}$, Philippe Ravier ${ }^{2}$ and Guy Lamarque ${ }^{2}$ \\ University of Tours (France), GREMAN CNRS UMR 7347 INSA CVL \\ 7 avenue Marcel Dassault, 37200 Tours (France) \\ Phone number: +33 2473613 24, e-mail: sebastien.bissey@univ-tours.fr, sebastien.jacques@ univ-tours.fr, \\ lebunetel@univ-tours.fr, sebastian.miranda@univ-tours.fr \\ University of Orléans (France), PRISME UPRES 4229 INSA CVL \\ 12 rue de Blois, 45100 Orléans (France) \\ Phone number: +33 2384948 63, e-mail: philippe.ravier@univ-orleans.fr, guy.lamarque@univ-orleans.fr
}

\begin{abstract}
The management of electricity consumption still represents a major issue, and particularly in individual housing mainly to find a good balance between production and consumption. Attention must be focused on the optimization of the cost of electricity consumption and, at the same time, the peak demand. Regarding a smart home management system, the inverter has a central role. Voltage and current bidirectional features are of utmost importance, specifically when an energy transfer is required from a storage system and the $A C$-grid, and vice versa. This article deals with an innovative bidirectional inverter topology based on sinusoidal waveforms from the generation of sine half-waves. The main challenges are both to improve the power quality of the output signals in terms of total harmonic distortion (THD), and minimize the complexity of the whole converter. Wide band-gap semiconductor devices ( $\mathrm{SiC}$ MOSFETs) are used to optimize the efficiency of the $D C$ - $A C$ converter while minimizing its size and its weight. Many experimental measurements with low output power (lower than $1 \mathrm{~kW}$ ) point out the relevance of this kind of topology.
\end{abstract}

\section{Key words}

Bidirectional inverter, power quality, THD, smart home management system.

\section{Introduction}

The depletion of fossil resources and the long-term increase on their price, the massive increase in energy needs, and the devastating impacts of climate change require a balance between the electricity production and the consumption modes of the end-users [1]. Nowadays, many solutions, particularly related to smart home energy management systems, already exist [2]. One of them consists in optimizing the cost of electricity consumption, while, at the same time, minimizing the peak demand [3]. Figure 1 shows a typical energy management system that may be implemented in individual housing.

The management of electricity consumption is here performed using a storage system, some sensors (temperature, presence etc.), and some smart switches used to drive the $A C$ loads. The aim is to cut off or defer the electrical energy consumption from the smart control of the storage system. Therefore, a $D C$ - $A C$ converter is necessary to act as the interface between the $A C$-grid and the storage system, and vice versa. In view of the ins quoted previously, a bidirectional inverter topology is mandatory.

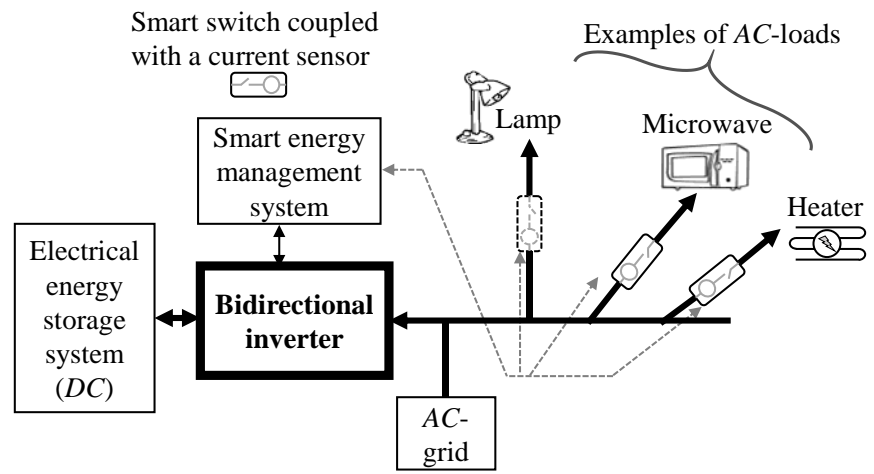

Fig. 1. Simplified illustration of a smart home

This article describes a new $D C$ - $A C$ converter topology to improve the power quality of output signals, particularly in terms of total harmonic distortion (THD). Multilevel inverters have been widely discussed in literature [4-6]. Such a topology is based on the partitioning of the $D C$-bus from several capacitors. The output voltage and the output current of a multilevel inverter are so composed of many intermediate levels. The higher the number of levels, the lower the THD of the output signals. However, the complexity of such a structure (number of electronic devices, number of capacitors...) can increase substantially.

In this paper, the ultimate challenge is to generate sinusoidal output signals from the combination of sine half-waves. The $3 \mathrm{~kW}$ bidirectional inverter described here uses wide band-gap semiconductor devices, and 
especially $\mathrm{SiC}$ MOSFETs which are controlled at a frequency of $300 \mathrm{kHz}$. The aim is also to optimize the efficiency of the inverter.

This manuscript is composed of two main sections. First of all, the functional analysis of the inverter is described. Finally, many experimental results with low output power (lower than $1 \mathrm{~kW}$ ) validate the main operation modes of the inverter.

\section{Functional analysis of the bidirectional inverter}

Figure 2 shows the architecture of the bidirectional $D C$ $A C$ converter. This kind of topology is based on the energy transfer between a $D C$ voltage source and an $A C$ one, and vice versa. Such an approach has been only partly exploited in published works [7-8].

\section{A. DC-DC stage}

Figure 3 gives the overall architecture of the $D C-D C$ stage of the inverter. The aim is to generate a rectified sine wave. The inductance named Lo (see Figure 2) is calculated to neglect the current ripple (which is the result of the switching frequency i.e., $300 \mathrm{kHz}$ ) in comparison with the low-frequency signal component (i.e., $50 \mathrm{~Hz}$ ). The $D C-D C$ converter is equivalent to a controllable current source, because the switching frequency is very high in comparison with the frequency of the $A C$-grid. As a consequence, the output current can be controlled by adjusting the voltage (named Vc [see Figure 2]) from an adaptive filtering stage. This adaptive filter is composed of several capacitors (C1, C2, C3 [see Figure 2]). It has a major interest, and especially when the output current decreases drastically. In such cases, it is possible to decrease the Vc-voltage. When the Vc-parameter is higher than the Vac-one (i.e., the $A C$ mains), the output current has a positive value, and vice versa. So, the electrical energy transfer is performed from the storage system to the $A C$-grid (inverter mode) or from the $A C$-grid to the storage system (rectifier mode).

The current trend is towards using wide band-gap semiconductor power devices. Those devices enable, among other things, to increase the switching frequency to optimize the compactness of the whole converter. The $D C-D C$ stage described in this paper is composed of $36 \mathrm{~A}$, $900 \mathrm{~V} \mathrm{SiC} \mathrm{MOSFETs}$ (C3M0065090D, Cree).

\section{B. DC-AC stage}

The $D C$ - $A C$ stage of the topology is in charge of inverting a half sine wave out of two to get a full sine wave output signal. This converter is composed of four $47 \mathrm{~A}, 500 \mathrm{~V}$ MOSFETs (IRFPS43N50KPBF, Vishay). Their switching frequency is equal to $50 \mathrm{~Hz}$. This low frequency enables the use of MOSFETs manufactured on a silicon substrate. The power devices' turning-on and off are performed with zero-crossing of the load current to reduce the losses.

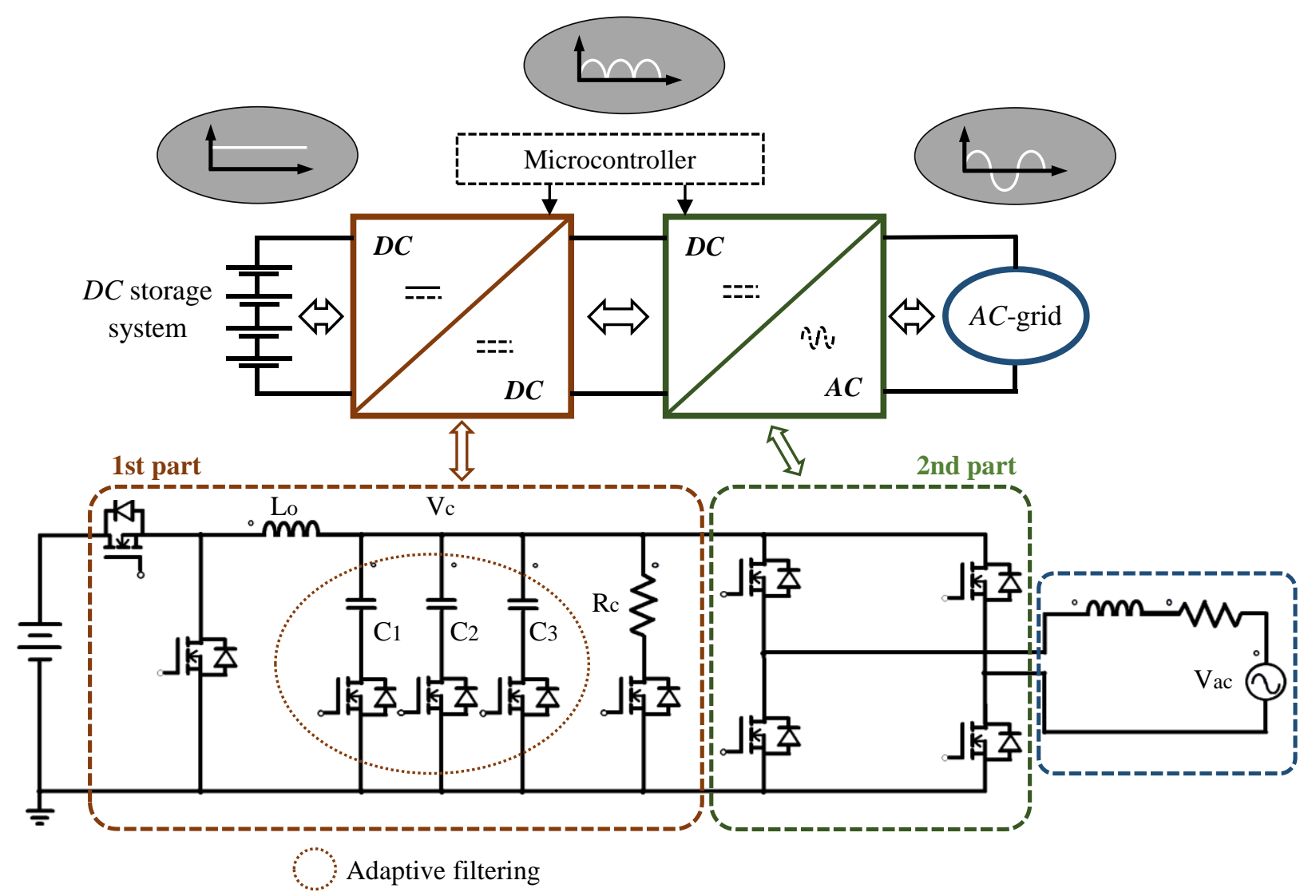

Fig. 2. Architecture of the bidirectional inverter 

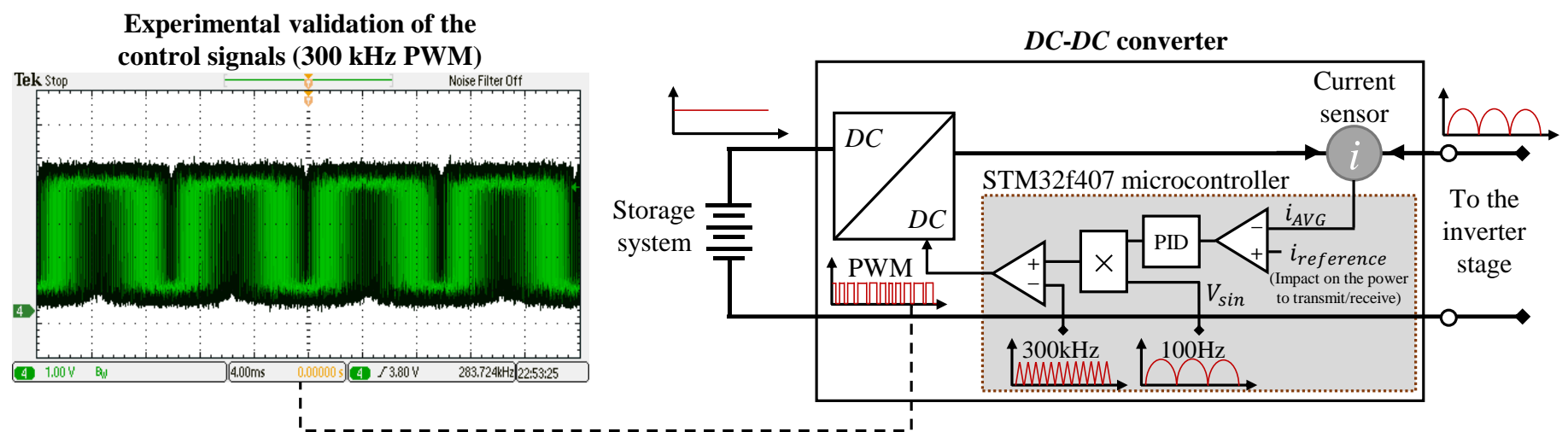

Fig. 3. Architecture of the $D C-D C$ stage

\section{Main experimental results and discussion}

\section{A. Experimental test procedure}

The operation modes of the inverter topology proposed in this article were validated at low power (lower than $1 \mathrm{~kW}$ ) through a complete experimental test procedure. Figure 4 gives the illustration of the experimental test bench. The storage system is simulated using a $3 \mathrm{~kW}$ programmable $D C$ power supply (reference: SM300-10, Delta Electronika) which has 2 independent outputs (each channel can be adjustable from 0 to $300 \mathrm{~V}$ for the voltage, and from 0 to $10 \mathrm{~A}$ for the current). Two demoboards were designed for the $D C-D C$ stage and the $D C-A C$ one, respectively. A resistive load $(1,300 \mathrm{~W}$ rheostat; from 0 to $11.5 \Omega ; 10 \mathrm{~A}$; reference: ECO2-106, Langlois) was used in the $D C$ - $A C$ stage to be sure that its main principle of operation was well contained. Of course, in the near future, the final demoboard of the whole system will be tested using non-linear loads.

A high voltage differential probe (reference: P5205, Tektronix), and a $15 \mathrm{~A} A C / D C$ current probe (reference: TCP202, Tektronix) were used to measure the output voltage and output current, respectively. The output power of the $D C-D C$ stage was measured using a watt meter (reference: PX 110, Metrix). Regarding the measurement of the output power of the $D C$ - $A C$ stage, the same type of electronic meter was used. Finally, the THD of the output voltage (or current) of the inverter was measured using a clamp-on harmonic power meter (reference: F27, Chauvin Arnoux).

To validate the main operation modes of the inverter, it is essential to measure the output voltage of the $D C-D C$ stage, the output voltage of the $D C-A C$ stage and its output current, to characterize the efficiency of the whole system, and measure the THD-parameter of the output voltage (and/or the output current).

\section{B. Main experimental results and discussion}

All experimental measurements discussed in this section of the article were performed in the following conditions:

- $\quad$ Input voltage ( $D C$ - $D C$ stage): $136 \mathrm{~V} \mathrm{DC}$.

- Output voltage: 74 V RMS.

- Output power: $300 \mathrm{~W}$.

- Load: rheostat, 10 A, $10 \Omega$.

Figure 5 shows the output voltage of the $D C-D C$ stage, and the output voltage and output current of the $D C-A C$ stage. In those experimental conditions, the THD of the output voltage is about $8 \%$. It is important to note that this result is lower than the typical value (about $37 \%$ for a 5-level inverter) reported in literature with roughly the same measurement conditions (output power about $440 \mathrm{~W})[4]$.

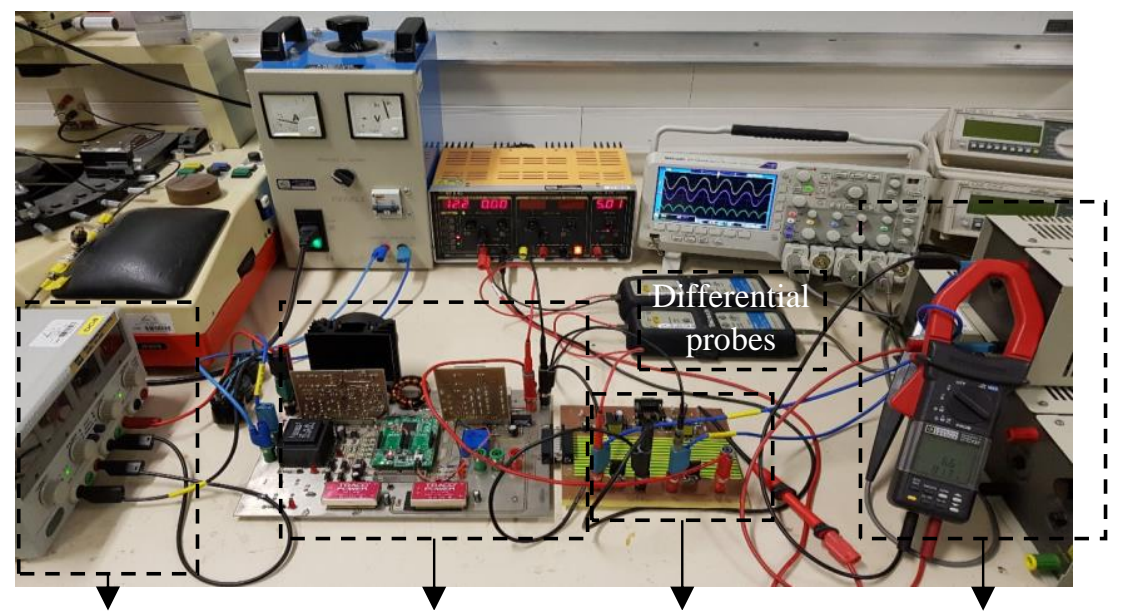

Programmable $D C$ power supply $(D C$ storage system)
$D C-D C$ stage

$D C$ - $A C$ stage

$1,300 \mathrm{~W}$ rheostat $+15 \mathrm{~A}$ $A C / D C$ current probe + clampon harmonic power meter

Fig. 4. Experimental test bench 


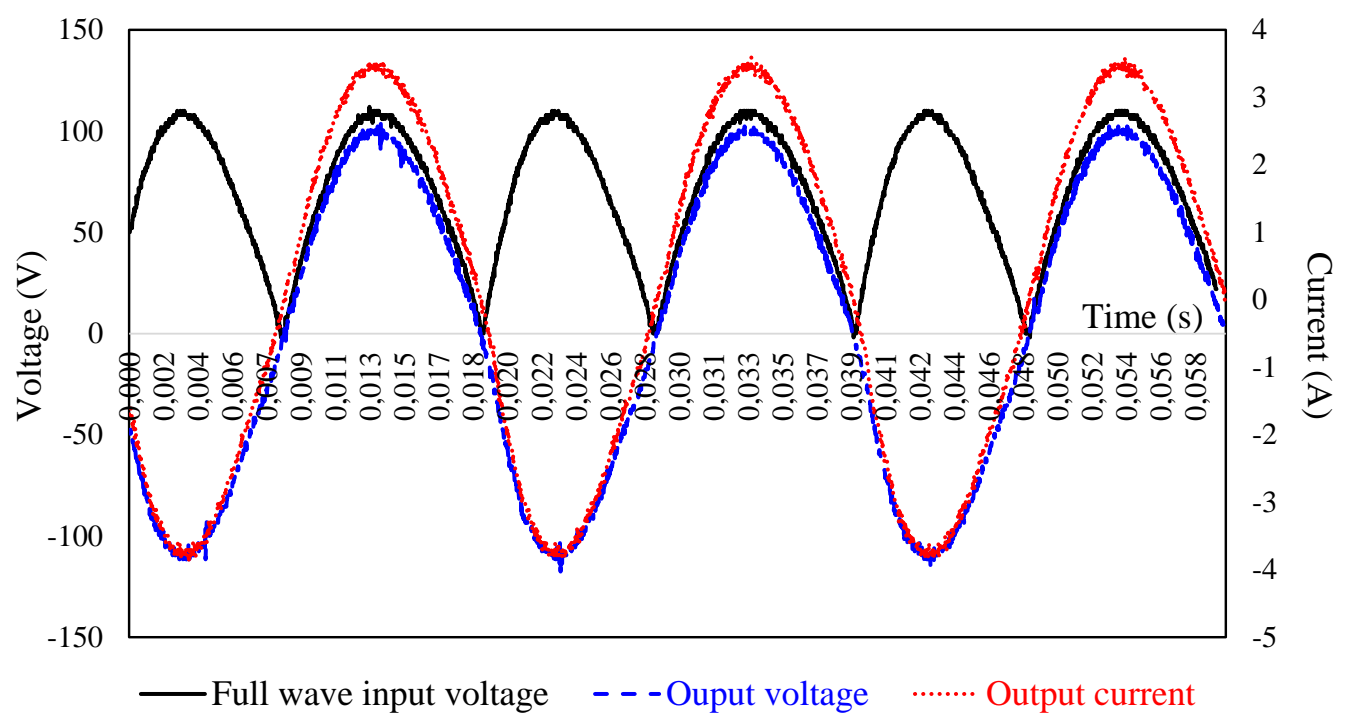

Fig. 5. Experimental measurements in the following conditions: $136 \mathrm{~V} \mathrm{DC}$ voltage, $74 \mathrm{~V}$ RMS output voltage, and $300 \mathrm{~W}$ output power

Figure 6 gives the evolution of the efficiency versus the output power, for both the $D C-D C$ stage and the whole inverter $(D C-D C$ and $D C$ - $A C$ stages). On average within the output power range, the efficiency of the $D C-D C$ stage is about $97.4 \%$, which is most satisfactory. Regarding the whole system ( $D C-D C$ and $D C$ - $A C$ stages), the average value of the efficiency is about $94.2 \%$ within the output power range (i.e., from $50 \mathrm{~W}$ to $650 \mathrm{~W}$ ). This value is necessarily lower, because the two stages of the whole inverter are in series. Despite this the efficiency of the whole system has very encouraging prospects.

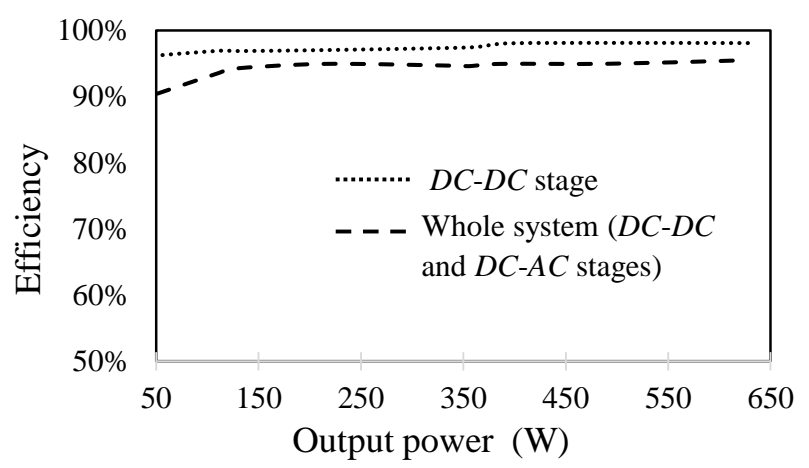

Fig. 6. Efficiency versus output power

\section{Conclusions}

An innovative bidirectional inverter topology was described in this article. This structure is based on the generation of full sine output signals from sine half-waves. The first experimental results with low output power (lower than $1 \mathrm{~kW}$ ) outline very positive prospects. In particular, the THD of the output signals is very low (about a few percent) in comparison with existing multilevel inverters reported in literature. Moreover, the efficiency of the whole system, which is about $94 \%$ on average within the output power range (up to $650 \mathrm{~W}$ ), is very promising.

Those results are significant because the relevance of the topology is now proven, but not reliable. Indeed, regarding the experimental procedure, a rheostat was used for the load. It is now crucial to connect the converter to the $A C$ grid. Finally, the operating modes of the inverter must be validated for its nominal power $(3 \mathrm{~kW})$. The complete results will be discussed in the near future.

\section{Acknowledgement}

These research activities are currently supported by "Région Centre Val-de-Loire" (research project number: 2015-00099656). The authors of this manuscript thank our colleagues from this institution who provided insight and expertise that greatly assisted the project.

\section{References}

[1] U.S. Energy Information Administration. International Energy Outlook 2017; U.S. Energy Information Administration: Washington, DC, USA, 2017.

[2] G. Pau, M. Collotta, A. Ruano, J. Qin, "Smart Home Energy Management", Energies 2017, 10, 382.

[3] S. Bissey, S. Jacques, J.-C. Le Bunetel, "The Fuzzy Logic Method to Efficiently Optimize Electricity Consumption in Individual Housing”, Energies 2017, 10, 1701.

[4] A. Caldeira, S. Jacques, A. Schellmanns, J.-C. Le Bunetel, N. Batut, L. Gonthier, "Development of a new mixed 5-level inverter for $3 \mathrm{~kW}$ household photovoltaic applications," Renewable Energy and Power Quality Journal., 2013, no. 11, pp. 1067-1072.

[5] S. Jacques, A. Caldeira, Z. Ren, A. Schellmanns, N. Batut, "New Multilevel Mixed Topology Development to Improve Inverter Robustness for Domestic Photovoltaic Installations," Journal of Power and Energy Engineering, 2013, Vol. 1, no. 5, pp. 1-6.

[6] K. K. Gupta, A. Ranjan, P. Bhatnagar, L. K. Sahu, S. Jain, "Multilevel Inverter Topologies With Reduced Device Count: A Review," IEEE Trans. Power Electron., 2016, vol. 31, no. 1, pp. 135-151.

[7] Zaohong Yang, "Bidirectional DC-to-AC inverter with improved performance," IEEE Trans. Aerosp. Electron. Syst., 1999, vol. 35, no. 2, pp. 533-542.

[8] E. Koutroulis, J. Chatzakis, K. Kalaitzakis, and N. C. Voulgaris, "A bidirectional, sinusoidal, high-frequency inverter design,” IEE Proc. - Electr. Power Appl., 2001, vol. 148, no. 4, p. 315 . 